\title{
VISUAL CULTURE: ANTENNA AND ROOTS
}

\author{
Maria Celeste de Almeida WANNER \\ Federal University of Bahia, School of Fine Arts, Brazil \\ mcawanner@hotmail.com \\ Valter Luis Dantas ORNELLAS \\ Federal University of Bahia, School of Fine Arts, Brazil \\ ornellas.valter@gmail.com
}

\begin{abstract}
The gap between the digital era in undeveloped places, in the 21 st century, is an important issue to be discussed. Based in the research called Antenna and Roots, developed at the Fine Art School at the Federal University of Bahia, Brazil, called Antenna and Roots, this paper proposes a dialogue between Visual Culture and contemporary visual languages, creative process, its methodology, and how the students are encourage to investigate with low tech equipments, certain that what makes a good art work is not only the equipment, but how an artist approaches material, equipments, etc., in order to materialize ideas, along the knowledge and understand about the world they live, without illustrating theories.
\end{abstract}

Keywords: Visual culture, Visual arts, Digital image, Antenna and Roots.

\section{INTRODUCTION}

The gap between the so called low and high technology can be seen in most of undeveloped countries in contrast with developed ones, where the increase of new equipments is extremely fast. This fact has two mainly aspect. One is the impact of the new technologies in many cultures with an invasion of all kind of machines, such as cellular phone, i-pads, compact and portable computer, wireless internet, etc. The second aspect is how those cultures may deal with this fast transformation in communication, in order to preserve its own traditional roots.

With the advance of digital technology, we are officially incorporating machine words as a universal language, and what we call now Visual Culture has many definitions and theories approaches in different areas of knowledge, as Science, Arts, Religion, Philosophy, etc.

When Socrates was opposed to the written word because it may erode memory, he believed that the switch from oral to written knowledge transmission would end up making people reliant on written documents as memory, and truth could be hard to distinguish. Now we are facing a challenge between written words, oral knowledge and machines memory. What Socrates actually voiced was the mistrust of new technology — or ideas, for that matter - a mistrust that has reemerged in the last 30 or 40 years as visual culture encroached on written culture.

While many scholars are studding the impact of digitalization on written language, others are turning towards visual languages, asking what we can do with the machine in order to be creative. It is well known that all machines are only instruments, and when the discussion is about visual arts, this issue has to be more considered, as the rise of new visual language, such as video and computer art, mediums that apply digital technology, since 1970. By that time, with a change in all areas of human knowledge, John Berger (1972) understood Visual Culture as mainly acknowledges the reality of living in a world of cross-mediation-where our experience of culturally meaningful visual content appears in multiple forms, and visual content and codes migrate from one form to another, i.e., the experience of everyday life can be described as code-switching or hacking the visual codes around us to navigate and negotiate meaning. Therefore, since the post-modern period, contemporary studies on Visual Culture has being focus in deconstruct potential visual/textual binary opposition, as most of 
our experience of media is a hybrid of texts, images, and sounds, rather than pure states of any one mode.

During that time, mostly by the end of 1960 s, the so called Fine Arts faced a great paradigm. Post-modern scholars, such as Rosalind Krauss in "Sculpture in the Expanded Field" (1983), Lucy Lippard's “The Dematerialization of The Art Object” (1968), and Arthur Danto (1998), who describes this period as "Pluralist", wrote a vast amount of articles and books. The concepts were applied to the all the new art practices outside the traditional canvas and sculpture, mostly performance, installation, earth and land art, video, computer art, and many others with its own hybridization of mediums.

\subsection{Antenna And Roots}

What does happen when digital equipment invades cultures where technological language is not yet well understood? What does happen to a rich visual culture society and the impossibility to follow what is called digital progress? How does society maintain its own visual culture and take advantage of progress, at the same time? Based in these questions our approach to Visual Culture in this paper aims to propose a reflexion about a research called Antenna and Roots.

As a full professor from the Fine Art School of the Federal University of Bahia, teaching at both graduate and undergraduate levels, it was very clear to see the student's desire to experiment with technology, in the beginning of 2000s. However, considering the sociofinancial aspect of a public university, as well as the financial condition of our country, we had to start to think how important was the digital equipments in art, and what could we do to work with them. Because of the so called low tech equipments became more popular and available, they could contribute to encourage students to create images with any kind of machine, softwares, with the understanding that a good art work does not rely only in the equipment, but how an artist approaches it in order to materialize his/her ideas, without illustrating any kind of theory.

Following the title-name of our project, the word antenna, that means the apparatus that transmit information, in a mostly fast way, in short time and space, is a metaphor word applied to progress. While root means a person or family as the source of offspring or descendants, a person's original or ancestral home, environment, culture, affinity for a place, habits, etc., that make a locale one's true home.

The "high art" world is both a source and destination for the whole of visual culture, but popular forms get rechanneled through art world validated art genres and venues, when we think about the hybridization of visual media. The Post-1980s expansion of art media and image technologies, mostly centered in digital images, or photography, can dialogue with other traditional visual practices and materials.

The contemporary visual languages, intrinsically, connects questions that involve man facing a world in constant development, globalized, multifaceted, technological, where the signs that represent things changes its meaning in function of spaces that they occupy temporarily or of a more lasting form.

The 21st century, unlike previous periods, allows a look to the past, democratically, and divides the same space without hierarchies. The gap of specific limits between material and techniques - before defined as "noble" - were part of the concept that characterized the transition of the post-modern transition. This transition became a great paradigm in the visual arts, when concepts of transformations, appropriation, hybridization, dematerialization, deconstruction, displacement and relocation became part of the new visual vocabulary, permitting to the artist occupy several positions and explore organizations of work that were not conditioned to an alone language. 
In that setting of changes in the formal structure of the visual arts, the impact of the happenings, performances, events, actions, videos, among others, surpassed the simple repertoire, affirming themselves as a language that permits to the artist expresses his interior world and the things that surrounded him/her.

Upon breaking the barriers and traditional limits, visual arts approached science, penetrating in diverse areas of the human knowledge, including the utilization of the machine as visual support - the technological art -, esthetics considered like one of the most expressive inventions in the history of the art.

According to Roy Ascott, in his essay called Is There Love in the Telematic Embrace? (apud Stiles, Selz, 1990, p. 491-492) the art in 1980 has been considered one as the most powerful computer technology, with video performances, video installations, etc.

Ascott also comments that this new approaches has influenced in human behavior, both in society as in his private life, and it has leading researches to question what is to be human being, what is creativity, how do people think and perceive, and finally how do people relate to each other and with the planet as a whole.

Since the advent of the first art video work, by Nam June Paik, in 1960, the artist was concerning with what Ascott described above, machine and man, as the following video makers, such and Bill Viola, has done ever since.

David A. Ross, Director of the San Francisco Museum of Modern Art, San Francisco, California, EUA, in a catalog, "Bill Viola - a 25-year Survey" (1999) explains that many people want to know about the means by which the art and the new technologies interact. For Ross, although Viola works with video equipment installations and hi-tech highly sophisticated computer, his themes at the same time, is universal. He talks about life, death, fire, water, earth, etc. The simple beauty, the impact visceral to eternal spirituality in his work is based in a spiritual worthy assembly, which has influenced deeply and continues providing its Buddhist Zen development, the Christian mysticism, to optical physical and the mechanisms of the perception, the Islamic lyrical poetry Sufi. His art achieves the origins of the knowledge that resides inside his everyday routine. Ross ends his presentation about Bill Viola work with this phrase: "Wherever you are is the entry point" - Kabir (1440-1518). Although it dates from the 15th century, this phrase of Kabir is considered a contemporary concept in digital languages, mostly at the internet, as a person can be at many different places at the same time.

However bringing this subject closer to the light of the Latin-American contemporary art, the authors Gerardo Mosquera and Mari Carmen Ramírez recognize that Identity in the context of globalization art scenery is a question conditioned to the legitimation, i.e., it must be understood in the configuration of new esthetics systems. For them, the circulation of the symbolic should be contained in an output as place of assertion of the supposed autonomy of the artistic field in order to be exercising their hegemonic power, transgressor of any dominant gesture. In "Beyond the Fantastic: Contemporary Art Criticism from Latin America", Gerardo Mosquera (1996) presents the global world as a paradox, a world of the difference.

The Latin-American art still remain analyzed by many art critics to the light of diverse theories, where its culture is linking to illustrative and merely stereotypical narrative. One of the most harmful consequences of the colonization is how they call native cultures through the Europeans, i.e., it is the interpretation of complex mental and cultural structures under the diffuse light of the ethnic fantasies of the colonizer. There is a lack of information about the importance of Latin American artist in the contemporary international art scenery. Those who 
recognize that can appreciate big exhibitions at major museum and galleries around the world, as well as the most famous biennials.

Joseph Kosuth (apud SANDLER, 1996, p. xxvii) considers that the artist is one of the most important representant of his/her culture:

It is the authenticity of the cultural production of a human being connected to his or her historical moment so concretely that the work is experienced as real; it is the passion of a creative intelligence to the present, which informs both the past and the future. It is not that the meaning of a work of art can transcend time, but that a work of art describes the maker's relationship to her or his context through the struggle to make meaning, and in so doing we get a glimpse of the life of the people who shared that meaning. [A] work of art must be so singularly the concrete expression of an individual (or individuals) that it is no longer simply about that individual, but rather, is about the culture that made such expression possible.

\subsection{Passage - An Installation}

The images that complement this paper illustrate the one of the many kinds of work that has been done in our group. In order to develop our work, we follow some basic methods, appropriate for the visual arts, mostly what we may call the relationship between the artist and his creative process; the relationship between the artist and the work.

Art works, frequently, are not exhausted in his initial proposal, in what concerns the first ideas of the artist. In this sense, it becomes part of our methodology to encourage the students to let the work takes its own directions, no matter how many they are. Each initial work can take many other forms. It can change from object to installations, it can be mixed together, since the working process to the final work, i.e. after installed in its exhibition spaces, they are still give many possibilities to grow and take others new artistic propositions.

For the solo show titled Passage, in May of 2011, in the Galeria Cañizares da Escola de Belas Artes da Universidade Federal da Bahia, in Brazil, Valter Ornellas elaborated an installation that illustrates our thought for this event.

The reason to present this work in the Conference Visualist 2012 is to show the many concepts of contemporary visual art, how this project was created, and the kind of materials were used, and finally how digitalization with low equipment can be an important matter.

Upon covering a whole room of the gallery with white transparent fabric (silk), from the ceiling to the floor, in a meander shape, the space became a passage where visitors could walk thought out the path. The sensation of haze was created with the quality of light, the scenery of transparence and brightness, that generated a mysterious expectation and anxious by what would be found to the end of the "journey". Figure 1

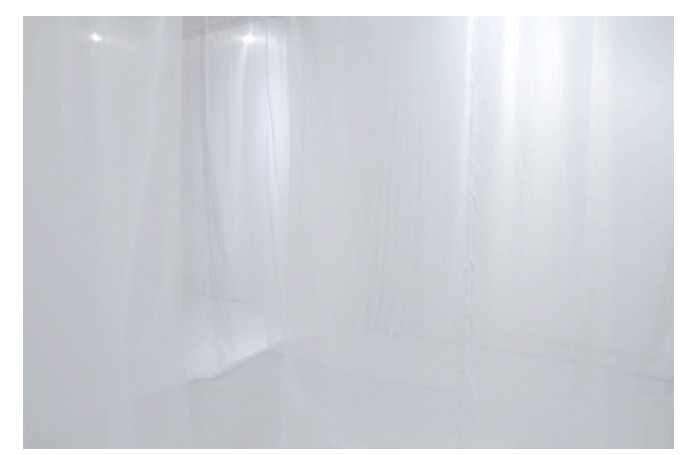

Figure 1 
The visitor had an opportunity to experiment with space, displacement, transparency, and a perception of being walking between moving walls, as the air caused by each participant walk interfere on the soft and light fabric. In this way, it could arouse many narratives for the work, with only few elements: space, fabric and light.

In this case the visitors became co-participants of the work, as his/her presence was part of the installation. Their shadow could be seeing from any point of the room, in different dimensions. Figure 2

The lack of horizon interfering many times as a body could appear floating in the mist or cloudy space.

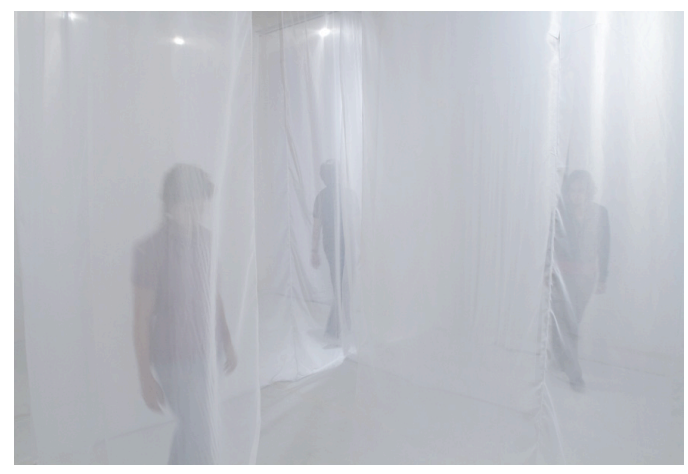

Figure 2

Due to its ephemeral condition, the whole scenery changed, provoked by the light inside the gallery, different people walking between the walls, the number of people, the lack of people, more or less lightning, shadows, movement etc. Figure 3

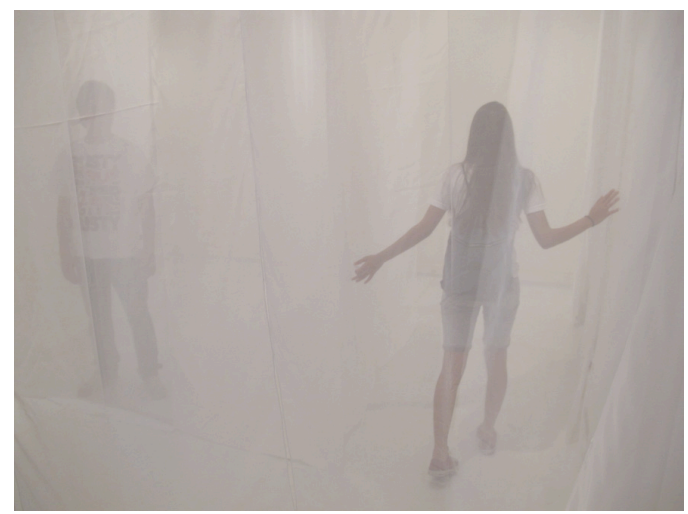

Figure 3

For the artist the installation was created to enable allusions to man as part of Nature. This theme brings others elements such as reference of Identity and Alterity, man and its environment, and the relationship between the mundane dimension and the transcendental dimension. From this point of view the concern with human relations continues illuminates and highlights many other issues.

Concerning the importance of the word root on this paper, prima face, we would like to say that "Passage" is a conceptual art work; therefore it does not tell a story step by step. The narrative is constructed by the visitors while co-participants of the work as much as the way they relate to it.

It goes without saying that the race in each country is a made by a complex form of individuals, and in Brazil the existence of a significant dimension of inequality is undeniable. The celebration of syncretism, especially in the state of Bahia, helps to the constructions of 
identity, with a great influence of African descendents. In this sense, people from this region can fairly be seen as under many different mixtures of colors, that goes beyond black or white. Consequently by the visitors or co-participants of this installation we can see the presence of our culture, in a very subtle way.

On the other hand, the installation experience gave an artist a chance to create other works. The panels gave a new idea: with an overhead projector and other digital projection equipments, images and texts were projected direct to these fragile walls. Figure 4 and 5

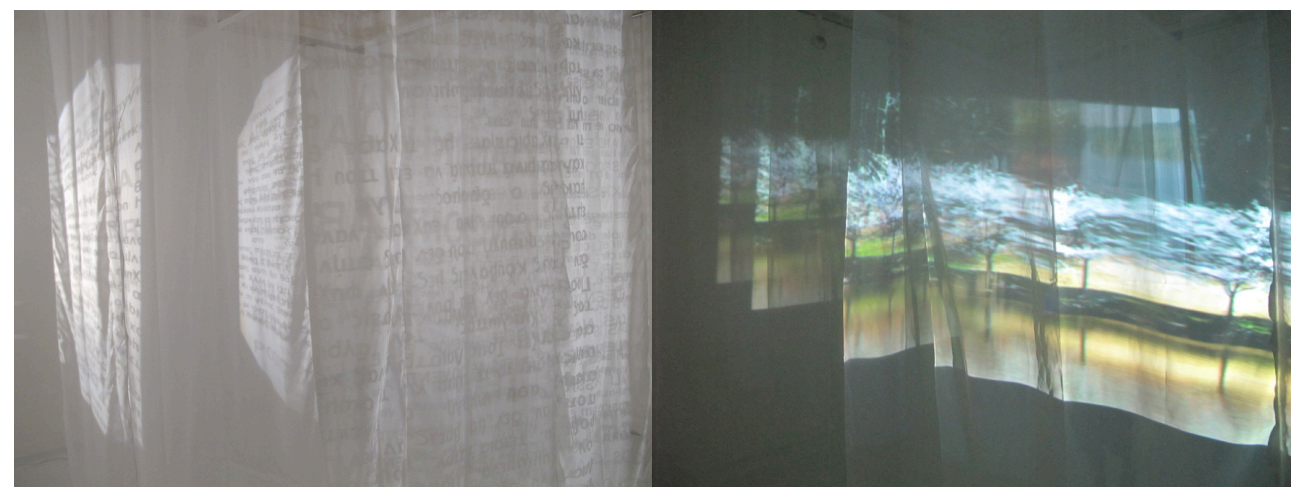

Figure 4-5

Most of the images of landscape and flowers were photographs by Maria Celeste de Almeida Wanner. Some of these flowers, such as the one bellow, are very popular in Bahia, and many times used in Afro Brazilian spiritual manifestations. Figure 6

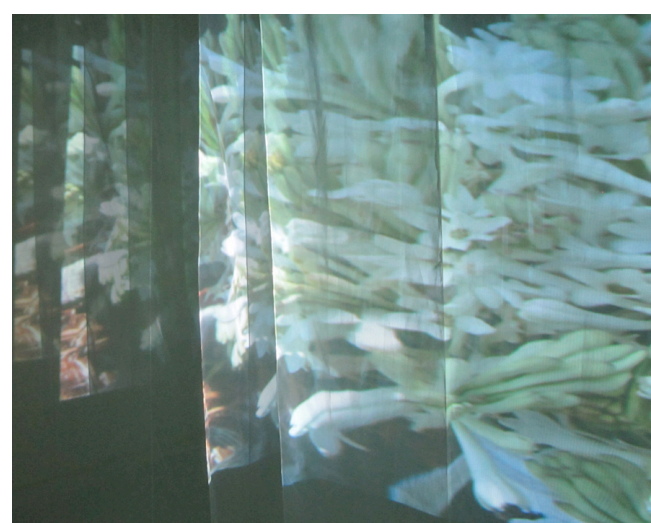

Figure 6

In order to register these moments it was necessary the use of photography and video. However these visual practices are not only and simple registration, but another visual language, as they are independent and defined by the intention and choice of the artist.

This Installation was also based in Gaston Bachelard's book; The Poetics of Space published in the 1960 s, where home remains a deeply symbolic space.

According to many reviewers, this book is a philosophical study of how space and our environment affect our understanding of ourselves and our society. It is many manifestations of "home" as both a tangible place and a place of dreams. The home acts as a shelter from outside forces as well as a space of the mind, one which inhabits an imagined as well as actual existence. As we encounter the manifestations of that space it affects our behavior and our understanding of both ourselves and our environment. Bachelard's theory acknowledges how the spaces in which we live begin to consume us, affect us, and help define who we are. By looking at corners, attics, stairways, and rooms, Bachelard addresses how different physical formations psychologically affect us. We are deeply affected by our environment and how we 
encounter each other depends upon this space. To describe a place as "home" is to acknowledge its relationship to ourselves, to create a mutual sense of belonging. The space of home is a sanctuary, a refuge from outside sources, but also, according to Bachelard, if that space is in some ways less than ideal the crooked nature of the house will create a life that is warped or changed by its environment. A small or oppressive physical living space can make us feel oppressed, uncomfortable and stifled.

It serves of grass to the winds. My house is diaphanous, but is not of glass. It would have before the constitution of the vapor. It walls condense and are expanded according my desire. But, sometimes, I leave the walls of my house to be expanded in the space of its own that is to extensibility infinite. The delirium permits that the image of home assumes lightness, "air lightness," as it was integrated to the wind. Winged home that interacts with the elements of the nature, as the wind. Then, other winds came around. Home of wind, dreamlike, of the caves and of the labyrinth. I would like that my house went similar to the wind of the sea, palpitating of seagulls. (Translation and selection of parts of citation by the authors) (Bachelard, 2008)

\section{REFERENCES}

Adams, L. (1966). The methodologies of art: an introduction. Colorado: Westview Press. Barnard, M. (2001).Approaches to Understanding Visual Culture. New York: Palgrave. Barrett, T. (2002). Interpreting Art: Responding to Visual Culture. London: Mayfield. Berger, J. (1972). Ways of seeing. Great Britain: Penguim Books.

Bachelard, G.(2008). A Poética do Espaço. Tradução: Antonio de Pádua Danesi. São Paulo: Martins Fontes.

Burgin, V. (1996). In/different Spaces: Place and Memory in Visual Culture. Berkeley: University of California Press.

Danto, A. (1998). The wake of art: criticism, philosophy, and the ends of taste. Amsterdan: $\mathrm{G}+\mathrm{B}$ Arts International Imprint.

Dikovitskaya, M. (2005). Visual Culture: the study of the visual after the cultural turn.

Cambridge, Mass: MIT Press.

Foster, H., Re: Post, in Wallis, Brian, Art After Modernism: Rethinking Representation, New York, The New Museum of Contemporary Art 1984, pp. 194-196.

Jenks, C.(1995).Visual Culture. London. New York: Routledge, 1995.

Krauss, R. Sculpture in the Expanded Field, in FOSTER, Hal (ed.), The Anti-Aesthetic, Essays on Postmodern Culture, Seattle, Washington, Bay Press, 1983, pp. 31-42 (orig. publ. in October $n^{\circ} 8$, Spring 1979).

Lippard, L. (1997). Six years: the dematerialization of the art object from 1966 to $1972 \ldots$ Berkeley: The University of California Press.

Mirzoeff, N.(2003). An Introduction to Visual Culture. New York: Routledge.

Sandler, I. (1996). Art of the postmodern era: From the late 1960s to the early 1990s. New York: Harper Collins.

Stiles, K., Selz, P (1996). Theories and documents of contemporary art. Berkeley: University of California Press.

Ross, D. (1999). Bill Viola - a 25-year Survey. San Francisco Museum of Modern Art, San Francisco, California, EUA.

Mitchell, W. J. T. "Showing seeing: a critique of visual culture," Journal of Visual Culture, 1, 2 (2002), 165-181; ref. on p. 173. 